\title{
Optimization of lead (II) removal in leachates using Moringa oleifera seeds
}

\author{
Mae Ann De Castro ${ }^{1}$, Cyril Ann Agripa ${ }^{1}$, John Raymond Barajas ${ }^{1 *}$, Faye Taniegra $^{2}$ \\ ${ }^{1}$ Bicol University, Department of Chemical Engineering, Legazpi City, Albay 4500, Philippines \\ ${ }^{2}$ Bicol University, Department of Business Administration, LegazpiCity, Albay 4500, Philippines
}

\begin{abstract}
The absence of comprehensive programs in regulating release of lead to the environment in growing cities situated in developing countries results to widespread intrusion of lead bioaccumulation in their primary sources of food. As a result, a significant increase in lead related diseases continually grows in many low income regions. In an attempt to provide a means of minimizing lead bioaccumulation, we test the extent to which Moringaoleifera seeds (MOS) removes lead (II) ions in aqueous solution. A boxbehnken experimental design was used to obtain the optimal conditions in the lead (II) removal process. MOS dosage, initial lead (II) concentration, and $\mathrm{pH}$ were found to have significant effects on the percent removal of lead (II) in solution. Actual values of these independent variables were chosen on the basis of preliminary experimental results. Optimum conditions were found to be: MOS dosage $10.0 \mathrm{~g} / \mathrm{L}$, initial lead (II) concentration $20.0 \mathrm{ppm}$, and $\mathrm{pH}$ at 5.5. Lead removal using MOS was also performed at optimal conditions. In conclusion, a high lead (II) removal using MOS strongly suggests its potential to be used as a means of treating liquids highly contaminated with lead.
\end{abstract}

\section{Introduction}

Rapid urbanization has been identified as a primary driving force that induces heavy metal contamination in the environment. Due to a significant increase in construction activities fuelled by economic growth and expansion, the volume of construction and demolition wastes (CDW) produced has grown exponentially. The European Union alone produces nearly 850 million tons of CDW annually [1]. Similarly, in 2014, the United States also produced CDW with the same magnitude [2]. It is estimated that with this cumulative amount of CDW, landfills would be filled to about $40 \%$ of their capacities [3]. The piling up of CDW in landfills, as a result, has driven the occurrence of heavy metal contamination in these dumping sites. Currently, toxic heavy metals (i.e. $\mathrm{Pb}$ ) in the leachate of landfills were found to be present at concentrations beyond $100 \mathrm{ppm}$ [4].If these toxic pollutants would remain at concentrations beyond threshold limits, areas near the perimeter of the dumping site and pristine matrices beneath the landfill would be at serious risks to heavy metal pollution.

Developing countries are seen to be most susceptible to heavy metal pollution. Since the economic growth of these countries relies heavily on the boom of the construction industry, an increase in the volume of CDW would also be expected. As a consequence, intrusion of heavy metals in the water distribution systems of these countries has been evident. For example, lead content of water sources in Metro Manila (Philippines) alone have doubled in just two years [5-6]. The observed abrupt

\footnotetext{
* Corresponding author: jrbarajas12@gmail.com
}

increase in lead concentrations can be attributed to the fact that lead contaminated leachates readily migrate from an open dumping site to pristine sources of water (i.e. groundwater)[7]. Due to the intake of leachate contaminated drinking water sources, about $21 \%$ of the children from pre-identified health districts all over the Philippines had elevated blood lead levels $(>10 \mu \mathrm{g} / \mathrm{dl})$ [8]. Collectively, these facts establish that the occurrence of heavy metal pollution can be directly linked to the economic development of a country [9]. Hence, a developing country needs to equip itself with adaptable and realistic measures to mitigate the negative impacts of its economic development and sustain its economic growth.

The use of Moringa olefeira (MO) seed extract has been identified as a water treatment technology suitable to the landscape of a developing country [10]. It has been demonstrated in literature that MO seeds contain active agents which have the capacity to sequestrate a variety of pollutants in water [11-12].Suarez et al. [13] have shown that the MO seed has the ability to inactive bacteria and flocculate other organic matter in water. In a different study, Ravikumar and Sheeja [14] have also noted that MO seeds can also sequestrate heavy metals in water. Although the use MO seed has been extensively used in water purification, its application as a treatment method to heavy metal contaminated leachates has been very limited. We contribute to research by investigating the capacity of MO seeds to treat leachates contaminated with lead metal. In the present work, we test the extent to which extracts from 
MO seeds can effectively remove lead ions in synthetic lead leachate solution. To assess the efficacy of MO seed use, we implemented a box-behnken experimental design to optimize lead removal in solution.

\section{Materials and methods}

\subsection{Materials and reagents}

Moringa oleifera seeds used in this study were purchased from local suppliers in Pangasinan, Philippines. Seeds of good quality were selected according to a criteria described in literature [15-16]. Shells and wings of the moringa seed were removed manually and the seed kernels collected were stored in a clean and dry box at room temperature. Seed kernels were powdered using a domestic blender on the day of each test to ensure the freshness of the seed. Chemical reagents (AR grade) used to prepare the synthetic leachate solution were purchased from Belman Laboratories. $\mathrm{PbCl}_{2}$ (AR grade) used was acquired separately from Yana Chemodities. Distilled water was used in all experiments.

\subsection{Preparation of Moringa oleifera seed extract}

Moringa extract stock solution $(5 \% \mathrm{w} / \mathrm{w})$ was prepared using a procedure combining methodologies described in published literature [17-18]. $10 \mathrm{~g}$ of powdered moringa seeds were partially wetted and mixed with $200 \mathrm{~mL}$ of 1 $\mathrm{M} \mathrm{NaCl}$ solution. The resulting paste was then diluted with $800 \mathrm{~mL}$ of $1 \mathrm{M} \mathrm{NaCl}$ solution and moderately stirred for 1 hour at room temperature. After mixing, the suspension was left undisturbed for another hour to allow free settling of heavy matter. The supernatant was then filtered and a clear white liquid was obtained. The filtrate collected was immediately used for experimentation to ensure full coagulant activity of the extract.

\subsection{Preparation of synthetic lead leachate solution}

Synthetic leachate was prepared to achieve a realistic COD: TN: TP ratio. The composition of the synthetic leachate was adopted from published literature [19-20]. Based on a 1-liter solution, the following amounts were added into water: $44.37 \mathrm{mg} \mathrm{K}_{2} \mathrm{HPO}_{3}, 967.96 \mathrm{mg}$ $\mathrm{KHCO}_{3}, 707.30 \mathrm{mg} \mathrm{K} \mathrm{CO}_{3}, 199.20 \mathrm{mg} \mathrm{NaCl}, 319.26 \mathrm{mg}$ $\mathrm{CaCl}_{2}, \quad 317.85 \mathrm{mg} \quad \mathrm{MgCl}_{2}{ }_{6} \mathrm{H}_{2} \mathrm{O}, \quad 160.73 \mathrm{mg}$ $\mathrm{MgSO}_{4} \cdot 7 \mathrm{H}_{2} \mathrm{O}, 8190.8 \mathrm{mg} \mathrm{NH}_{4} \mathrm{HCO}_{3}$, and $714.36 \mathrm{mg}$ $\mathrm{NaHCO}_{3}$. The mixture was stirred until equilibrium was reached. Once the prepared leachate is equilibrated, known volumes of lead solution $\left(\mathrm{PbCl}_{2}\right.$ and distilled water) were added into the mixture to achieve lead concentrations of 2, 11, and $20 \mathrm{ppm}$. Aqueous concentrations of lead were checked using a Perkin Elmer Lambda 45 UV-Vis spectrophotometer. Lead ions in solution were detected at a wavelength of $211 \mathrm{~nm}$ [21]. On the day of each test, fresh lead leachate solutions were used to minimize the effects of leachate age.

\subsection{Experimental design}

A box-behnken experimental design (see Table 1 and Table 2) generated using Stat-Ease design expert software was implemented to investigate the influence of independent variables (coagulant dosage $\mathrm{g} / \mathrm{L}$; $\mathrm{pH}$; initial lead concentration ppm) in optimizing the desired response (lead removal \%). All experimental runs were performed in duplicates.

Table 1. Independent Variables Influencing Lead Removal

\begin{tabular}{lccc}
\hline \multirow{2}{*}{ Factor } & \multirow{2}{*}{ Unit } & \multicolumn{2}{c}{ Factor level } \\
\cline { 3 - 4 } & & Low & High \\
\hline Coagulant Dosage & $\mathrm{g} / \mathrm{L}$ & 10 & 100 \\
Initial Lead Concentration & $\mathrm{ppm}$ & 2 & 20 \\
$\mathrm{pH}$ & - & 2 & 9 \\
\hline
\end{tabular}

Table 2. Box-Behnken Design Experimental Runs

\begin{tabular}{|c|c|c|c|}
\hline Run & $\begin{array}{c}\text { Factor 1 A: } \\
\text { Coagulant } \\
\text { Dosage (g/L) }\end{array}$ & $\begin{array}{c}\text { Factor } 2 \text { B: Initial } \\
\text { Lead } \\
\text { Concentration } \\
\text { (ppm) }\end{array}$ & $\begin{array}{c}\text { Factor } 3 \\
\text { C: } \mathbf{p H}\end{array}$ \\
\hline 1 & 55 & 20 & 2 \\
\hline 2 & 55 & 2 & 2 \\
\hline 3 & 55 & 11 & 5.5 \\
\hline 4 & 55 & 11 & 5.5 \\
\hline 5 & 10 & 11 & 2 \\
\hline 6 & 100 & 11 & 2 \\
\hline 7 & 55 & 11 & 5.5 \\
\hline 8 & 55 & 2 & 9 \\
\hline 9 & 100 & 2 & 5.5 \\
\hline 10 & 10 & 20 & 5.5 \\
\hline 11 & 55 & 11 & 5.5 \\
\hline 12 & 10 & 2 & 5.5 \\
\hline 13 & 100 & 11 & 9 \\
\hline 14 & 10 & 11 & 9 \\
\hline 15 & 55 & 11 & 5.5 \\
\hline 16 & 100 & 20 & 5.5 \\
\hline 17 & 55 & 20 & 9 \\
\hline
\end{tabular}

\section{Results and discussion}

\subsection{Preliminary experimental tests}

Factor levels used in the box-behnken experimental design were based on the chemical characteristics of lead contaminated leachate $[\mathbf{5 - 6}, \mathbf{1 9 - 2 0}]$. A one-factor-at-atime (OFAT) approach was used to determine whether these selected values can be replicated in controlled conditions. To test whether lead can be flocculated by MOS, trials were performed at an initial lead 
concentration of 2 and $20 \mathrm{ppm}$. As shown in Figure 1, MOS readily removed lead in the leachate solutions dosed with lead contamination. It is noted however that percent lead removal decreases as coagulant dosage decreases. The saturation of MO coagulants in solution may have induced electrostatic repulsion between lead and MO coagulant molecules alike [22]. Hence, optimum solution conditions to achieve maximum percent lead removal may likely be at lower dosages of MOS.

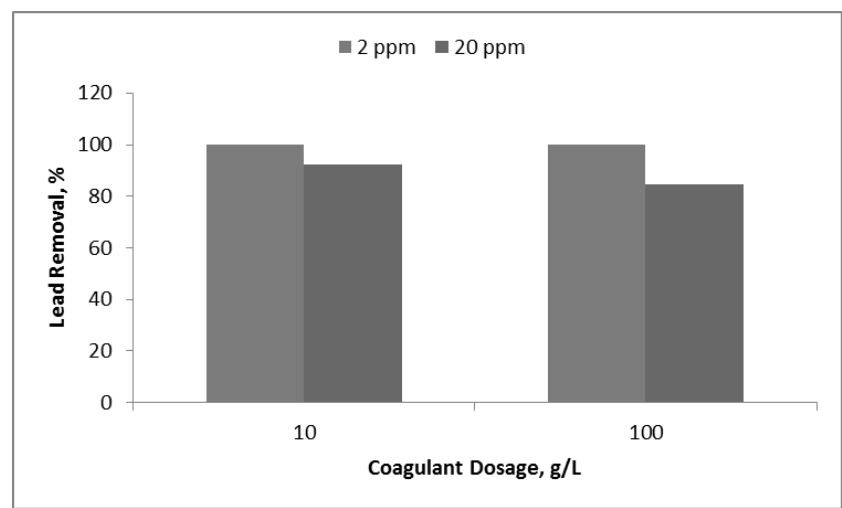

Figure 1. Results of Preliminary Experiments; temperature $25^{\circ} \mathrm{C}$; mixing time 30 minutes; solution volume $300 \mathrm{~mL} 3.2$ Statistical Tests and Mathematical Model Building

\subsection{Statistical tests and mathematical model Building}

A 12-run box-behnken experimental design with three factors was used to develop an appropriate empirical model which would predict lead removal at any desired factor level combinations. 5 center points were added to capture the stability and inherent variability in the removal lead in solution using MOS. Design Expert 11 Software ${ }^{\circledR}$ (Stat-Ease, USA) was used to generate a second-order response empirical equation. This model (p-value $<0.0001$ ) with the actual factors is given in Eq. 1.

$$
\begin{aligned}
& \ln \frac{\text { \% removal }}{100-\% \text { removal }} \\
&=\text { Intercept }+C_{1} A+C_{2} B \\
&+C_{3} C+C_{4} A B+C_{5} A C+C_{6} B C \\
&+C_{7} A^{2}+C_{8} B^{2}+C_{9} C^{2} \\
&+C_{10} A^{2} B+C_{11} A B^{2}
\end{aligned}
$$

where A corresponds to the factor coagulant dosage $(\mathrm{g} / \mathrm{L}), \mathrm{B}$ is the factor initial lead concentration (ppm), C is the factor $\mathrm{pH}$, and $\mathrm{C}_{1}$ to $\mathrm{C}_{11}$ are coefficients with values summarized in Table 3 .

As shown in Table 4, the predicted values are in close agreement with the observed values. To test whether the developed empirical model was sound, Design Expert 11 Software ${ }^{\circledR}$ was used to statistically analyze the validity of the model.
Table 3. Values of Coefficients in the Empirical Model

\begin{tabular}{cccc}
\hline Term & $\begin{array}{c}\text { Coefficient } \\
\text { Values }\end{array}$ & p-value & Remarks \\
\hline Intercept & 1.6610 & - & - \\
$\mathrm{A}$ & 0.1271 & $<0.0001$ & Significant \\
$\mathrm{B}$ & -0.07958 & 1.0000 & Not Significant \\
$\mathrm{C}$ & 2.0000 & 0.0001 & Significant \\
$\mathrm{AB}$ & 0.001124 & $<0.0001$ & Significant \\
$\mathrm{AC}$ & 0.006479 & $<0.0001$ & Significant \\
$\mathrm{BC}$ & $5.863 \times 10^{-18}$ & 1.0000 & Not Significant \\
$\mathrm{A}^{2}$ & 0.0006177 & $<0.0001$ & Significant \\
$\mathrm{B}^{2}$ & 0.001042 & $<0.0001$ & Significant \\
$\mathrm{C}^{2}$ & -0.1362 & $<0.0001$ & Significant \\
$\mathrm{A}^{2} \mathrm{~B}$ & -0.0001030 & $<0.0001$ & Significant \\
$\mathrm{AB}^{2}$ & 0.0003555 & $<0.0001$ & Significant \\
\hline
\end{tabular}

Table 4. Observed and Predicted Values from the BoxBehnken Experimental Design

\begin{tabular}{ccccccc}
\hline Run & A & B & C & Observed & Predicted & \%Error \\
\hline 1 & -1 & -1 & 0 & 99.99 & 99.99 & 0.00 \\
2 & 1 & -1 & 0 & 99.99 & 100.00 & 0.01 \\
3 & -1 & 1 & 0 & 99.99 & 99.99 & 0.01 \\
4 & 1 & 1 & 0 & 84.55 & 99.99 & 18.28 \\
5 & -1 & 0 & -1 & 99.41 & 99.73 & 0.32 \\
6 & 1 & 0 & -1 & 69.38 & 99.98 & 44.10 \\
7 & -1 & 0 & 1 & 99.99 & 99.99 & 0.00 \\
8 & 1 & 0 & 1 & 69.38 & 99.99 & 44.14 \\
9 & 0 & -1 & -1 & 99.99 & 99.97 & -0.02 \\
10 & 0 & 1 & -1 & 99.99 & 99.99 & 0.01 \\
11 & 0 & -1 & 1 & 99.99 & 99.99 & 0.01 \\
12 & 0 & 1 & 1 & 99.99 & 100.00 & 0.01 \\
13 & 0 & 0 & 0 & 99.99 & 99.99 & 0.01 \\
14 & 0 & 0 & 0 & 99.99 & 99.99 & 0.01 \\
15 & 0 & 0 & 0 & 99.99 & 99.99 & 0.01 \\
16 & 0 & 0 & 0 & 99.99 & 99.99 & 0.01 \\
17 & 0 & 0 & 0 & 99.99 & 99.99 & 0.01 \\
\hline
\end{tabular}

As presented in Table 5, an $\mathrm{R}^{2}$ value that is close to unity indicates a good fit of the model. Furthermore, the adjusted and predicted $\mathrm{R}^{2}$ are in good agreement with each other. This strongly suggests that there is a strong correlation between the predicted outcomes and the observed values.

Table 5. Statistical Fit of the Empirical Model

\begin{tabular}{llll}
\hline \multicolumn{4}{c}{ Fit Statistics } \\
\hline Std. Dev. & 0.4406 & $\mathbf{R}^{2}$ & 0.9872 \\
Mean & 7.5416 & Adjusted $\mathbf{R}^{2}$ & 0.9808 \\
C.V. \% & 5.8412 & Predicted $\mathbf{R}^{2}$ & 0.9595 \\
\hline
\end{tabular}




\subsection{Optimization of lead removal}

With the empirical model validated, percent lead removal was then maximized. Since it was previously noted that percent lead removal decreased as MOS dosage is increased, the percent lead removal was maximized at a coagulant dosage of $10 \mathrm{~g} / \mathrm{L}$ and at an initial lead concentration of $20 \mathrm{ppm}$. As shown in Figure 2, a lower coagulant dosage was predicted to still give high percent removal of lead. Further, based on the 3D surface given in Figure 3,99.99\% lead removal would be expected with the given factor combinations. To confirm this predicted response, confirmatory experimental runs werealso done at the given factor level combinations. Based from the results of these runs, an error of less than $1 \%$ was noted between the majority of the predicted and observed results. However, the obtained model does not predict well at higher coagulant dosages (i.e. $100 \mathrm{~g} / \mathrm{L}$ ). Recorded errors for trials dosed at $100 \mathrm{~g} / \mathrm{L}$ of MOS were very high which ranged from $40-50 \%$. These results were parallel to the previously observed behavior noted in the preliminary experiments performed. Nevertheless, a good agreement between the predicted and observed response persists and this further strengthens the validity of the generated empirical model.

\section{Conclusion}

Utilization of MOS in removing lead contaminated leachate is a viable alternative method that can be administered in developing countries. With the MO trees being relatively abundant in the tropics, it is somehow strategically placed in these low-income regions. We contribute to research by providing evidences that MOS can effectively sequester lead in leachate solutions.
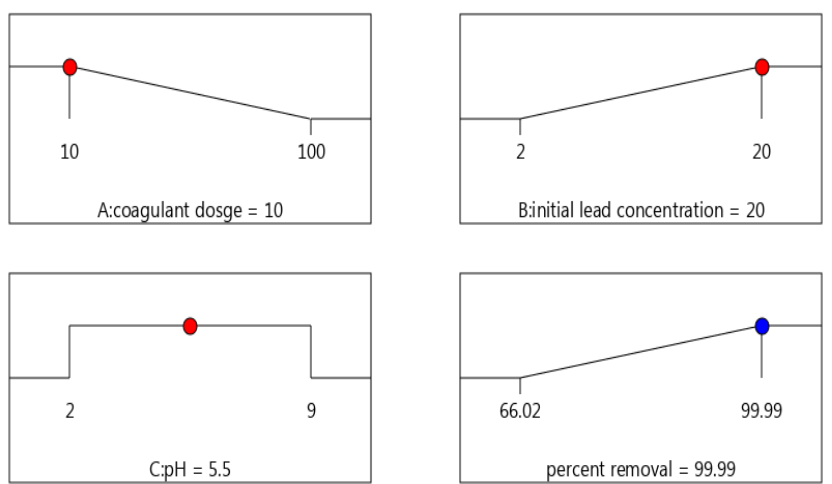

Figure 2. Factor Level Combination to Predict Maximum Lead Removal

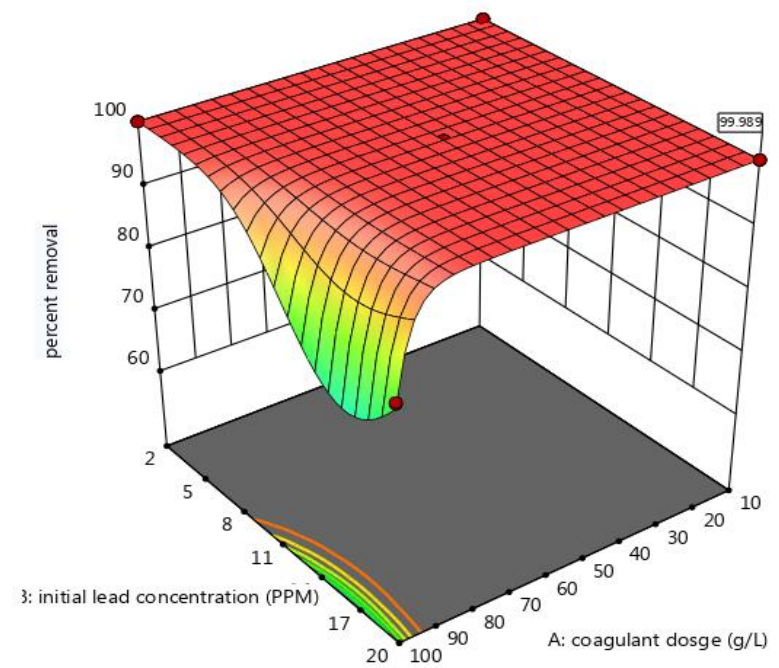

Figure 3. 3D Response Surface for Percent Lead Removal

These findings suggest that higher dosages of MOS have a negative uptake on the percent removal of lead in solution. We then presented an empirical model wherein percent lead removal is maximized at low dosages of MOS. Optimum conditions we found in this study were: coagulant dosage $10 \mathrm{~g} / \mathrm{L} ; \mathrm{pH} \quad 5.5 ;$ and initial concentration of lead $20 \mathrm{ppm}$.

We would like to thank Bicol University College of Science for allowing us to use their UV-Vis spectrophotometer and Bicol University College of Engineering - Chemical Engineering Department for granting us permission to use their facilities.

\section{References}

[1] Fischer C. and Werge M. EU as a Recycling Society: Present Recycling Levels of Municipal Waste and Construction \& Demolition Waste in the EU, Copenhagen, 2009.

[2] United States Environmental Protection Agency, Construction and Demolition Debris Generation in the United States, U.S Office of Resource Conservation and Recovery, 2016, pp. 23.

[3] Yang H., Xia J., Thompson J.R., and Flower R.J. Urban construction and demolition waste and landfill failure in Shenzhen, China, Waste Management 63, 2017, 393 - 396.

[4] Zhang H., He P.J., and Shao L.M. Implication of heavymetals distribution for a municipal solid waste management system-a case study in shanghai, The Science of the Total Environment 402, 2008, 257267.

[5] Solidum J. and Solidum G. Assesment and remediation of heavy metals in community tap water from Manila, Philippines, 2012 International Conference on Environmental Science and Engineering, Singapore, 2012, 1-6.

[6] Solidum J., Dahilig V.R., and Omran A. Lead levels 
ofwater sources in Manila, Philippines, Annals of faculty engineering hunedoara - International Journal of Engineering (VIII), 2010, 111-118.

[7] Kanmani S. and Gandhimathi R. Assesment of heavy metal contamination in soil due to leachate migration from an open dumping site, Applied Water Science 3, 2013, 193-20.

[8] Available online at http://www.who.int/bulletin/volumes/85/9/06036137/en/

[9] Flegal A.R. and Smith D.R. Lead levels in pre-industrialhumans. The New England Journal Of Medicine 326, 1992, 1293-1294.

[10] Santos, J. R., Pagsuyoin, S. A., and Latayan, J. S. A multi-criteria decision analysis framework for evaluating point-of-use water treatment alternatives. Clean Technologies and Environmental Policy, 2015, 1-17.

[11] Ndabigengesere, A. I., Narasiah, S., and Talbot, B. G. Active Agents and Mechanism of Coagulation of Turbid Waters Using Moringaoleifera.Water Research 29(2), 1995, 703-710.

[12] Muyibi, S. A., and Evison, L. M. Moringaoleifera Seeds for SofetningHardwater.Water Research29(4), 1995, 1099-1105.

[13] Suarez M., Haenni M., Canarelli S., Fisch F., Chodanowski P., Servis, C. and Mermod, N. Structure-Function Characterization and Optimization of a Plant-Derived Antibacterial Peptide.Antimicrobial Agents and Chemotherapy 49(9), 2005, 3847-3857.

[14] Ravikumar K. and Sheeja A.K. Heavy metal removal from water using moringaoleifera seed coagulant and double filtration, International Journal of Scientific \& Engineering Research 4(5), 2013, 10-13.

[15] Katayon S., MegatMohd Noor M. J., Asma M., AbhulGhani L. A., Thamer A. M., Azni I., Ahmad J., Khor B. C. and Suleyman A. M. Effects of storage conditions of Moringaoleifera seeds on its performance in coagulation, Bioresource Technology 97, 2006, 1455-1460.

[16] Jahn, S. A. Using Moringa seeds as coagulants in developing countries, Journal of the American Water Works Association 80, 1988, 43-50.

[17] Barajas J., Latayan J., Pagsuyoin S., Bacani F., Santos

J., Tan R., Orbecido A., Razon L., and Almendrala M. Water disinfection using moringa protein adsorbed on rice husk ash, Systems and Information Engineering Design Symposium SIEDS, 2016, 16-19.

[18] Sanchez-Martin J., Beltran-Heredia J., and Peres J. A. Improvement of the flocculation Process in water treatment by using Moringaoleifera seeds extract,
Brazilian Journal of Chemical Engineering 29(3), 2012, 495-501.

[19] Bracklow U., Drews, A., Vocks, M., and Kraume, M. Comparison of nutrients degradation in smallscale MBR fed with synthetic/domestic wastewater, Journal of Hazardous Materials 144(3), 2007, 620626.

[20] Nacera, Y., and Aicha, B., Kinetic models for the sorption of dye from aqueous solution by claywood sawdust mixture, Desalination 185(3), 2005, 499508.

[21] Tan C. H., Moo Y.C., Matjafri M.Z., and Lim H.S. UV spectroscopy determination of aqueous lead and copper ions in water, The International Society for Optical Engineering, 2014.

[22] Belfort, G., and Lee, C. S., Attractive and repulsive interactions between and within adsorbed ribonuclease A layers, Proceedings of the National Academy of Science USA, 1991, 9146-9150. 